\title{
Foreword: The Play's the Thing
}

The last thirty years have been a seminal period of critique, rethinking, and experimentation with anthropology's sustaining genre form the ethnography. A key concern of this activity has been to create texts that enliven dialogue between ethnographer/subject/audience, and in so doing challenge the traditional authority of texts. In place of one authorial voice, we have sought forms for ethnography that offer polyphonic representation, wherein informants are not paraphrased but speak for themselves (see Clifford and Marcus 2010). In the 1980s, inspired by Bakhtin and other, especially feminist, thinkers, there was hope for the multi- or co-authored experiment in writing. There were a few, and some notable, exemplars of ethnographic texts written in dialogic form, that is, in a manner that shared the authorial voice between ethnographer and ethnographic subjects. Since that moment, ethnography, though considerably expanded in its narrative and analytic imaginaries, has largely remained in its textual monologic tradition (that is, giving primacy to the voice of the ethnographer). Yet, during that same period, there were alternatives on the margins, including pioneering theater anthropology - Conquergood, the Turners, Fabian, among others - and the steady development of ethnographic film and media beyond strictly observational commitments. A coalescence of these working traditions brings into view a different "post" moment than the one we imagined in the late twentieth century. Hartblay's work, for one, shows us, definitively, that we have arrived at such a moment. 
Nothing did, and still nothing has (and perhaps nothing should have?) shaken the rite-de-passage of the observational fieldwork project - leading to the genre ethnography with experimental moves within limits - as the entre into anthropological careers. Yet, in this volume, Hartblay's account of her parallel development as theater/ performance artist and first-project anthropologist makes for extraordinarily valuable and absorbing reading, more so in that we have arrived at a time when discussions of alternative ("multi-modal") forms for producing career qualifying ethnographic research are under lively discussion.

Hartblay's contribution here shows that the formal modes of professional reception of ethnographic research in anthropology responding to the textual artifacts of research - are enhanced by other episodes, acts, studios, para-sites, third spaces of reception, response, and commentary to authoritative, analytic argument from fieldwork in the making. This is what the contemporary development of performance/theater anthropology offers - though without any certainty that such a venture as Hartblay develops here ever "docks" back in academic debate according to the latter's authority. With suspenseful uncertainty, the script inventions of Hartblay and their development out of what began as canonical ethnographic research moves in exciting directions of its own through theatrical production. Where fieldwork realized in theater projects eventually intersects with the demands of ethnographic analytics is an exciting and suspenseful dimension of Hartblay's work in motion.

This work demonstrates and articulates brilliantly how different ways of working, defining ethnographic projects, evolve from the still canonical fieldwork project. Having produced an ethnographic dissertation from fieldwork, with a promissory of written ethnography in the future, Hartblay first creates this extraordinary volume of performance/theater ethnography, seeding into it a vivid account of her engagements with Russia, its language, recent history, and cultural understandings of disability - all told through the experience of the disabled interlocutors entangled in a society bound to mistake them. In so doing, she deeply involves the reader in performance, dialogue, and polyphony, all the while feeding the contexts of fieldwork and ethnography into her presentation and commentary on the script. 
Hartblay is deeply in artistic and writerly control of the shaping of her own unique text, and me saying more in the manner of a "foreword" will only get in the way of a clear strategy of presentation (beginning with a brief "Note from the Ethnographer") and a remarkable essay, with a set of diverse but extraordinarily valuable appendixes (including one that expertly shows how any teacher or instructor might integrate performative, theatrical elements practically into a variety of classroom/seminar situations).

However, I have perhaps one helpful suggestion for the reader about to set out on the carefully organized, absorbing course that Hartblay has set for us. It makes complete sense, and is perhaps the convention, to open with/expose the reader first to the playscript, followed by photos, before launching into an essay that is foreword, introduction, extended critical essay, and practical guide all in one. However, as with many others I know, I am a problematic reader of play transcripts - the magic for me is only in the live performance. While I was easily absorbed in reading the introductory account/ short monograph that follows the script, I struggled to follow the dialogue of the play with reading alone. Going back to the script following the other sections of the book and watching the performances, I had more to work with. For instance, revisiting the script with Hartblay's explanation of the Russian concept of oporniki in mind, I read the interactions between characters differently.

Watching performances brought me closer to the sensory power of polyphonic ethnography that has generated such a brilliantly designed and explained project. I recommend readers encountering this text for the first time to perform or view performances of the text to enliven the script's dynamic potential.

So as a de facto contemporary historian of anthropological textuality, with a longing for performative dimensions of the stuff of ethnographic research that the printed page only can incompletely satisfy, I Was Never Alone or Oporniki is a challenging, absorbing breakthrough.

George E. Marcus, University of California, Irvine co-editor, Writing Culture (1986) co-author, Designs for an Anthropology of the Contemporary (2008) co-author, Ethnography by Design: Scenographic Experiments in Fieldwork (2019) 
